\title{
Desconstrução e construção conjunta de relato biográfico: Ideação e Avaliatividade na perspectiva sistêmico-funcional
}

\author{
Desconstruction And Joint Construction Of A Biographical Recount: Ideation And Appraisal In The Systemic- \\ functional Pers \\ pective
}

\section{Cristiane Fuzer}

Universidade Federal de Santa Maria - UFSM - Rio Grande do Sul - Brasil

\section{Anidene de Siqueira Cecchin}

Universidade Federal de Santa Maria - UFSM - Rio Grande do Sul - Brasil

\begin{abstract}
Resumo: Este trabalho parte de uma pesquisa-ação em contexto escolar, com alunos do $9^{\circ}$ ano do Ensino Fundamental, que envolveu atividades de Desconstrução e Construção conjunta, as quais integram o Ciclo de Ensino e Aprendizagem da Pedagogia com base em Gêneros de Texto da Escola de Sydney. A partir de uma abordagem qualitativa, analisamos as duas versões do texto produzido conjuntamente pelos participantes, com o objetivo de verificar a aproximação ao propósito sociocomunicativo e à estrutura esquemática do relato biográfico a partir dos recursos linguísticos típicos desse gênero, na perspectiva da Linguística Sistêmico-Funcional. A análise focaliza, no componente verbal, os sistemas semântico-discursivos de Ideação e Avaliatividade e a comparação das duas versões quanto aos estratos contextual, semântico-discursivo e gramatical do sistema linguístico.
\end{abstract}

Palavras-chave: Pedagogia de Gênero. Ciclo de Ensino e Aprendizagem. Relato biográfico. Ideação. Avaliatividade.

\begin{abstract}
This work stems from an action research in school context, with lower secondary education (grade 9) students, involving Deconstruction and joint Construction activities, which integrate the Teaching and Learning Cycle based on Textual Genres from Sydney School. Through a qualitative approach, we analyzed both versions of the text produced jointly by the participants, aiming at verifying the closeness to the sociocommunicative proposal and the schematic structure of the biographical recount considering the typical linguistic resources of this genre within the Systemic-Functional Linguistics perspective. The analysis focuses, with respect to the verbal component, on the Ideation and Appraisal semantic-discursive systems and on the comparison of the two versions in terms of the context, semantic-discursive and grammatical strata of the linguistic system.
\end{abstract}

Keywords: Genre Pedagogy. Teaching and Learning Cycle. Biographical recount Ideation. Appraisal. 


\section{Introdução}

Por muitas vezes tem se mencionado, em discursos acadêmicos e documentos oficiais, a necessidade de um "ensino contextualizado da linguagem". $\mathrm{Na}$ BNCC (BRASIL, 2018), são recorrentes expressões como "domínio contextualizado de gêneros" (BNCC, p. 147), "aprendizagens de modo contextualizado e significativo para os estudantes" (p.244), "domínio progressivo e contextualizado de procedimentos de pesquisa e de gêneros" (BNCC, p. 515). Como proceder para um ensino contextualizado da língua portuguesa em contexto escolar? Diferentes abordagens teórico-metodológicas são utilizadas para desenvolver propostas e procedimentos de ensino e aprendizagem conforme sua perspectiva de linguagem e letramento. Neste trabalho, baseamo-nos na perspectiva da Linguística Sistêmico-Funcional para mostrar como pensamos e praticamos o ensino contextualizado da língua portuguesa em atividades de leitura e escrita para a educação básica.

Por meio do projeto de ensino e extensão Ateliê de Textos (FUZER, 2016a), têm se desenvolvido, desde 2011, atividades de leitura e escrita de diferentes gêneros de textos em língua portuguesa. Foram publicadas, até metade de 2020, dez coletâneas com os textos produzidos por alunos dos anos finais do Ensino Fundamental, participantes das oficinas de produção textual, promovidas em 21 escolas públicas no sul do Brasil. O projeto ${ }^{1}$ tem como base teórico-metodológica princípios da Linguística Sistêmico-Funcional (HALLIDAY, 1985; HALLIDAY, 1994; HALLIDAY e MATTHIESSEN, 2014), com foco na Pedagogia com base em Gêneros de Texto, ancorada na abordagem que ficou conhecida como Escola de Sydney (ROSE; MARTIN, 2012; CHRISTIE; DEREWIANKA, 2008). As atividades são organizadas conforme o Ciclo de Ensino e Aprendizagem, que prevê três momentos fundamentais: Desconstrução do texto, Construção conjunta e Construção individual.

${ }^{1} \mathrm{O}$ projeto é itinerante e, por isso, a cada ano altera-se o número de alunos e escolas atendidas. Em 2020, as atividades foram realizadas totalmente na modalidade remota, devido à necessidade de distanciamento social
A partir da prática realizada na oitava edição do Ateliê de Textos, no ano de 2018, com estudantes do $9^{\circ}$ ano do ensino fundamental, apresentamos, neste artigo, uma reflexão sobre atividades de Desconstrução e Construção conjunta de texto que instancia o gênero relato biográfico em língua portuguesa. $\mathrm{O}$ trabalho com esses dois momentos do Ciclo de Ensino e Aprendizagem da Escola de Sydney envolveu a produção de um caderno didático CECCHIN; FUZER, 2018) com atividades de preparação para a leitura, a fim de orientar os alunos sobre o propósito sociocomunicativo, a estrutura esquemática do gênero (etapas e fases) e as principais características linguísticas do relato biográfico, preparando-os, assim, para a leitura e escrita de textos desse gênero.

O foco de análise, neste artigo, são as versões escrita e reescrita do texto resultante da estratégia Construção conjunta que foi precedida por atividades de modelagem na estratégia Desconstrução de textos que instanciam o gênero relato biográfico (MARTIN e ROSE, 2008), na perspectiva da Linguística SistêmicoFuncional (HALLIDAY; MATTHIESSEN, 2004, 2014). Para verificar a aproximação do texto produzido conjuntamente pelos alunos ao domínio do gênero relato biográfico, analisamos recursos dos sistemas semântico-discursivos de Ideação e de Avaliatividade na versão escrita e reescrita.

A relevância deste trabalho vai ao encontro da necessidade de fortalecer e unificar a proposta de ensino da linguagem alicerçada na Linguística Sistêmico-Funcional e na metodologia da Pedagogia com base em Gênero de Texto, em contexto educacional brasileiro, conforme destaca Vian Jr (2013). Desse modo, torna-se importante não só mostrar o desenvolvimento dessa abordagem teóricometodológica e as contribuições para a Linguística Aplicada brasileira, ampliando o escopo de estudos já realizados (PIRES, 2017; OLIVEIRA, 2019; SANTORUM, 2019, entre outros), mas também avaliar a aprendizagem de recursos linguísticos em contexto evidenciada nos textos produzidos por estudantes que

imposta pela pandemia da COVID-19. As ações e os textos analisados neste artigo, porém, foram produzidos em 2018, na modalidade presencial. 
experienciaram estratégias do Ciclo de Ensino e Aprendizagem (ROSE e MARTIN, 2012). Entendemos que a relação dialética entre teoria, metodologia e prática situada em contexto, conforme propõe a perspectiva sistêmico-funcional, possibilita 0 desenvolvimento da consciência linguística não só dos alunos, que serão conduzidos passo a passo e de modo cooperativo no processo de leitura e escrita, como também do professor, que precisará, no planejamento das aulas, proceder à análise das escolhas linguísticas nos textos a serem usados na modelagem do gênero para, então, desenvolver atividades de preparação para a escrita e avaliar os textos dos alunos com base em critérios compatíveis com o propósito e as características do gênero de texto utilizado. A própria escolha do gênero de texto a ser utilizado se tornará mais pertinente aos níveis de letramento - ao nível em que os alunos se encontram e ao que se pretende que alcancem.

A partir de uma abordagem qualitativa, de caráter interpretativista, são analisadas ocorrências linguísticas dos sistemas semântico-discursivos de Ideação (MARTIN, 1992; MARTIN; ROSE, 2007) e de Avaliatividade (MARTIN; WHITE, 2005) por serem considerados pela bibliografia prévia (MARTIN e ROSE, 2008) os mais relevantes para o alcance do propósito do gênero relato biográfico.

O artigo está organizado em quatro seções. Inicialmente, apresentamos uma síntese dos principais pressupostos teóricos que fundamentaram as atividades propostas. A seguir, descrevemos as ações metodológicas realizadas para o planejamento e a execução das atividades de ensino e aprendizagem, em forma de oficina, na escola parceira, bem como os procedimentos de análise das duas versões do texto produzido conjuntamente pelos participantes. $\mathrm{Na}$ sequência, reportamos a análise e a discussão dos dados gerados. Por fim, apresentamos considerações

\footnotetext{
2 Em língua portuguesa, informações sobre os principais gêneros de texto utilizados em diferentes áreas disciplinares do ensino básico e superior de Portugal vêm sendo disponibilizadas no "Portal de Géneros Escolares \& Académicos" (https://sites.ipleiria.pt/pge), do Núcleo Temático Discurso e Práticas Discursivas Acadêmicas (DPDA) do Centro de Estudos de Linguística Geral e Aplicada da Universidade de Coimbra (CELGA-ILTEC).
}

finais sobre a prática com base no estudo realizado.

\section{Fundamentação teórico-metodológica}

Para a elaboração das atividades de preparação para a leitura e escrita no contexto escolar, conforme Pedagogia com base em Gêneros da Escola de Sydney (ROSE; MARTIN, 2012), e para a descrição e análise do texto resultante da dinamização dos momentos de desconstrução e construção conjunta do Ciclo de Ensino e Aprendizagem, foram utilizados como aporte teórico princípios da Linguística Sistêmico-Funcional (HALLIDAY; MATTHIESSEN, 2014).

\subsection{Pedagogia com base em Gênero e Ciclo de Ensino e Aprendizagem}

A Pedagogia com base em Gênero da Escola de Sydney propõe o ensino explícito da língua em funcionamento nos textos, por meio de atividades de leitura e escrita que ajudam os estudantes a adquirirem conhecimentos e habilidades que lhes possibilitem produzir textos cada vez mais próximos ao domínio do gênero. Essa proposta pedagógica vem sendo construída e aprimorada desde a década de 1980 por meio de projetos realizados em contexto escolar australiano por um grupo de pesquisadores coordenado por Martin (ROSE; MARTIN, 2012). A versão mais recente dessa proposta de letramento se encontra no programa Reading to Learn, coordenado por David Rose, que disponibiliza, em uma plataforma on-line (https://www.readingtolearn.com.au), resultados de pesquisas sobre gêneros de textos ${ }^{2}$, ebooks e DVDs de treinamento na metodologia proposta.

Inspirados na pedagogia construtivista de Vygotsky e no modelo organizacional com base em

No Brasil, informações sobre implementações da metodologia com foco em gêneros das famílias das estórias e histórias na educação básica, bem como resultados de pesquisa, estão disponíveis no site institucional do projeto de extensão "Ateliê de Textos" (www.ufsm.br/ateliedetextos). 
níveis, definidos como códigos linguísticos pelo sociólogo Bernstein, pesquisadores da Escola de Sydney adotam os dispositivos pedagógicos de distribuição, recontextualização e avaliação para delinear um ensino da linguagem capaz de prover as necessidades de diferentes grupos de estudantes, com diferentes níveis de habilidades de escrita, para cumprir propósitos comunicativos na sociedade (ROSE; MARTIN, 2012). Para isso, é utilizado o Ciclo de Ensino e Aprendizagem, proposto inicialmente por Rothery (1996) e redesenhado por Rose e Martin (2012), a fim de orientar o processo de produção de textos, tendo por base as etapas cíclicas de Desconstrução, Construção conjunta e Construção individual (Figura 1).

\section{Figura 1: Ciclo de Ensino e Aprendizagem}

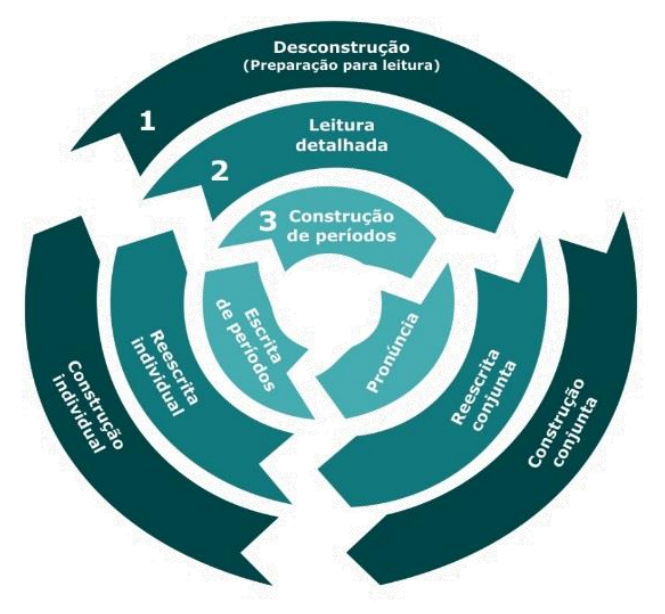

Fonte: traduzido de Rose e Martin (2012) por Fuzer (2016b, p.09).

Não há uma sequência estanque para o trabalho com as etapas do Ciclo. O professor pode começar pela etapa mais conveniente aos objetivos de ensino. No caso do presente trabalho, optamos por iniciar pela etapa de Desconstrução, propondo atividades que levassem os estudantes a identificar a estrutura esquemática e o propósito sociocomunicativo do gênero, bem como explorar os recursos linguísticos que o constituem e o caracterizam.

A partir dessas atividades, passamos para a Construção conjunta, em que os alunos produziram um texto do mesmo gênero estudado na etapa anterior. Durante a Construção conjunta, é importante o papel desempenhado pelo professor como orientador e mediador do processo para a seleção de ideias em forma de texto. Após a escrita e reescrita conjunta, os estudantes produzem, durante a Construção individual, de forma mais autônoma, um texto do mesmo gênero trabalhado. Essa etapa pode ser a primeira a ser implementada nos casos em que se busca realizar uma avaliação diagnóstica da escrita dos estudantes e, depois de implementadas as demais estratégias do Ciclo, ser realizada novamente. Essa dinâmica possibilita ao professor comparar a primeira produção dos alunos com a última, a fim de aferir avanços na aprendizagem de determinados aspectos da linguagem do gênero de texto utilizado.

Essa proposta metodológica possibilita 0 ensino explícito da gramática de uma língua tendo em vista padrões de linguagem que constituem gêneros de texto, além de envolver professores e estudantes no processo de construção de conhecimento sobre e com a linguagem. Dessa forma, o estudante desenvolve habilidades linguísticas para a leitura e produção de textos que se aproximam do domínio do gênero de texto em estudo. Em outras palavras, aprendem a usar adequadamente recursos linguísticos para o alcance de determinado propósito sociocomunicativo.

Para a dinamização dessa pedagogia no contexto escolar, considerado neste trabalho, usamos como ponto de partida recursos linguísticos tipicamente usados no gênero relato biográfico, cujo propósito é reportar eventos da vida de uma pessoa. Para a realização do propósito, as informações são apresentadas em etapas de gênero, que Martin e Rose (2008) descrevem na sequência Orientação^Eventos^ ${ }^{\wedge}$ Reorientação. Cada uma das etapas pode se constituir de diferentes fases, pelas quais as informações sobre a vida da pessoa biografada vão sendo desdobradas ao longo do texto (isso está demonstrado na seção Análise e discussão). 
2.2 Princípios para análise da escrita e da reescrita: sistemas semântico-discursivos de Ideação e de Avaliatividade,

O estudo dos sistemas semântico-discursivos possibilita explorar os significados produzidos em textos, considerando os aspectos situacionais. A partir das relações semânticas construídas em um texto, diferentes significados se revelam e permitem identificar os valores que constituem a vida das pessoas e o papel que essas construções representam na sociedade (MARTIN, 1992; MARTIN; ROSE, 2007). Com base nas relações estabelecidas pelos fenômenos linguísticos no texto e a forma como estes se organizam sob diferentes ângulos, que se complementam na construção de significados, Martin (1992), tendo por base a teoria sistêmico-funcional de Halliday (1985). propôs seis sistemas semânticodiscursivos: Ideação, Avaliatividade, Conjunção, Identificação, Periodicidade e Negociação (MARTIN, 1992; MARTIN; ROSE, 2007). Como o foco do presente estudo está nos sistemas de Ideação e Avaliatividade, passamos a discorrer sobre estes dois sistemas.

O sistema semântico-discursivo de Ideação refere-se à forma como os significados experienciais (materiais, mentais, relacionais, verbais, comportamentais e existenciais ${ }^{3}$ ) são representados no texto em atividades nas quais as pessoas se envolvem no contexto social, tendo em vista as escolhas que realizam, os processos dos quais participam, os lugares e as pessoas com que se relacionam e as qualidades que envolvem esse contexto. Na Ideação, o ponto de partida é o léxico, que é percebido a partir da perspectiva sintagmática de organização do sistema discursivo (MARTIN, 1992). Nesse sentido, as relações lexicais desempenham um importante papel na forma como o discurso se estrutura e são identificadas a partir das relações taxonômicas e nucleares.
As relações taxonômicas são construídas entre os itens lexicais e sua progressão no texto, conforme o tipo de taxonomia que estabelecem. Classificam-se em superordenação, com base na subclassificação dos itens lexicais, e em composição, para abordar a relação das partes que compõem o todo de um texto. As relações nucleares, por sua vez, são determinadas pela configuração de elementos centrais dentro de cada oração e a forma como coisas, pessoas e lugares se organizam. A partir disso, relações taxonômicas e nucleares constroem sequências de atividades, que configuram eventos e compõem o campo do texto no qual os participantes estão envolvidos.

O campo de experiência de um texto, conforme Martin (1992), alicerçado em Halliday (1985), é o ponto de partida para identificar a natureza da ação social e indicar o que está acontecendo, isto é, as atividades nas quais os participantes do texto se envolvem e os processos em que se engajam sequencialmente. O campo de experiência constitui-se de atividades sequenciadas, compostas por ações que se configuram com a participação de pessoas, lugares e coisas e podem ser sequenciadas no tempo. De acordo com Martin (1992), um texto pode apresentar mais de um campo de experiência - um é sempre dominante, e os demais são denominados subcampos.

O sistema semântico-discursivo de Avaliatividade refere-se à avaliação construída pela linguagem e aos significados interpessoais compartilhados no contexto (MARTIN, 1992, MARTIN; ROSE, 2007). Esse sistema focaliza as trocas e as negociações realizadas entre as pessoas no momento em que interagem umas com as outras. Nesse sentido, a avaliação está relacionada aos valores e aos sentimentos partilhados no contexto de forma explícita ou implícita no texto, em palavras, grupos de palavras ou orações (MARTIN; WHITE, 2005). Os recursos de Avaliatividade organizam-se em três subsistemas: Engajamento, Atitude e Gradação.

1994) e revisado juntamente com Matthiessen (2004, 2014).
3 Os significados ideacionais são realizados, estrato léxico-gramatical do sistema linguístico, pelo sistema de transitividade, conforme descrito por Halliday (1985, 
Para a análise aqui proposta, recorremos ao subsistema Atitude, haja vista sua expressiva contribuição na realização do propósito sociocomunicativo do gênero relato biográfico. As avaliações de Atitude revelam como a linguagem é usada para expressar emoções (afeto), para julgar comportamento e caráter das pessoas ou instituições (julgamento) e para valorar coisas, eventos ou pessoas (apreciação). Os significados avaliativos são registrados de forma positiva ou negativa, os quais se apresentam explícitos ou implícitos no texto.

\section{Relato da dinamização e procedimentos de análise}

Para este trabalho, adotamos o método de pesquisa-ação, no qual o pesquisador se insere no contexto investigado e interage com os demais participantes durante seu processo de desenvolvimento, a fim de construir conhecimento. De acordo com Thiollent (2011, p. 110), "essa metodologia é concebida como a articulação do conhecer e do agir", é uma ação transformadora, que se configura a partir de um constante processo de ação-reflexão-ação.

Os textos que são objetos de análise, neste trabalho, são a versão produzida na atividade de escrita conjunta e a versão produzida na reescrita conjunta. Esse momento de produção coletiva foi antecedido por atividades de Desconstrução do gênero e seguido pela escrita e reescrita individual, ambas realizadas em forma de oficina promovida pelo projeto de ensino e extensão Ateliê de Textos (FUZER, 2016a) em parceria com um projeto de pesquisa de doutorado (CECCHIN, 2017), que foi submetido previamente ao Comitê de Ética na Pesquisa da Universidade Federal de Santa Maria/RS, Brasil (CEP/UFSM), e aprovado sob o CAAE número 73059317.9.0000.5346.

A oficina foi desenvolvida em encontros semanais de duas horas, em turno inverso às aulas regulares, no Instituto São José, na cidade de Santa Maria/RS, Brasil, durante o segundo semestre letivo de

\footnotetext{
${ }^{4}$ Primeira autora deste artigo

${ }^{5}$ Segunda autora deste artigo
}

2018. Essa escola recebe alunos de diferentes localidades da cidade de Santa Maria/RS e funciona com professores cedidos pela Rede Pública Estadual e Municipal. Em contrapartida, o Instituto atende alunos de baixa renda, disponibilizando bolsas de estudos.

Os participantes da dinamização foram a idealizadora e coordenadora do projeto Ateliê de Textos $^{4}$, que orientou todo 0 processo de planejamento, produção e execução das atividades; a professora de Língua Portuguesa da turma e pesquisadora ${ }^{5}$, que participou da produção e execução da oficina; uma aluna do curso de graduação em Letras Licenciatura em Língua Portuguesa e Literaturas, que participou da execução da oficina, e alunos do $9^{\circ}$ ano do Ensino Fundamental, público-alvo do projeto beneficiado com as atividades desenvolvidas, com idade entre 14 e 16 anos. Esses alunos foram convidados a participar voluntariamente do projeto, com a devida autorização de seus responsáveis.

A primeira parte do trabalho consistiu na produção de atividades de leitura detalhada que pudessem ser utilizadas no momento de Desconstrução, conforme o Ciclo de Ensino e Aprendizagem, com base em Rose e Martin (2012). Para isso, foram utilizados resultados de uma análise prévia de dois textos considerados representativos do gênero relato biográfico multimodal, publicados no site Museu da Pessoa ${ }^{6}$. As atividades foram organizadas em um caderno didático (CECCHIN; FUZER, 2018), que contém explicações sobre o propósito, as etapas e os recursos linguísticos típicos do gênero de texto em estudo e uma série de questões para a leitura e análise de textos que conduzem ao estudo dos seguintes aspectos: variáveis do contexto de situação (HALLIDAY, 1985); participantes do texto, processos em que estão envolvidos (especialmente a pessoa biografada) e circunstâncias que localizam os eventos espaço-temporalmente (HALLIDAY; MATTHIESSEN, 2014; MARTIN; ROSE, 2007); recursos avaliativos que

\footnotetext{
${ }^{6}$ http://www.museudapessoa.net/pt/home
} 
contribuem para a representação da pessoa biografada (MARTIN; WHITE, 2005).

O caderno didático foi disponibilizado impresso aos alunos participantes da oficina, para nortear a leitura e o processo de preparação para a escrita e reescrita nos momentos subsequentes do Ciclo. Foram realizados quatro encontros sucessivos, de duas horas, uma vez por semana, para que os participantes concluíssem as atividades propostas no caderno didático. Essas atividades compreendiam o estudo do componente verbal e do componente visual de dois textos, previamente selecionados, no site Museu da Pessoa.

Ao finalizarem as atividades de Desconstrução, deu-se início à escrita conjunta. Para isso, foi escolhida para ser biografada uma pessoa conhecida por todos os alunos do grupo, com a qual foi realizada uma entrevista gravada em áudio. $\mathrm{Na}$ coleta de informações sobre a biografada, os participantes utilizaram as orientações propostas no caderno didático e iniciaram a entrevista, que teve a duração de uma hora. À medida que a biografada respondia às perguntas, novos questionamentos surgiam, eram incorporados na conversa e registrados em um bloco de notas.

$\mathrm{Na}$ sequência, foi desenvolvida a escrita conjunta, em dois encontros sucessivos - um para o planejamento e a escrita da primeira versão do texto e outro para a revisão e reescrita. A primeira versão foi produzida no encontro seguinte ao da entrevista. Para isso, o áudio com a gravação da conversa foi disponibilizado aos participantes para que ouvissem antes do encontro. Durante a escrita conjunta, os alunos iam negociando ideias e selecionando informações que constavam na entrevista. Com o auxílio das mediadoras da oficina, distribuíam e articulavam textualmente as informações selecionadas, seguindo as etapas do gênero, conforme estudado nas atividades de Desconstrução. Um dos alunos ia digitando no computador as frases sugeridas pelos demais alunos, projetadas no
Datashow, de modo que todos poderiam ir acompanhando o planejamento e desenvolvimento do texto.

Após a escrita da primeira versão, no encontro seguinte, o grupo recebeu um feedback em forma de bilhete orientador ${ }^{7}$, que buscou auxiliar na realização de ajustes para maior aproximação ao domínio do gênero relato biográfico. Seguindo as sugestões propostas, os alunos procederam à reescrita conjuntamente. A segunda versão do texto foi publicada na coletânea Pessoas especiais, Histórias extraordinárias (CECCHIN; MOURA; FUZER, 2018).

Para a análise das duas versões do texto produzido conjuntamente, consideramos a abordagem qualitativa de análise interpretativista, visto que buscamos investigar "o universo dos significados, motivos, aspirações, crenças, valores e atitudes" (MINAYO, 1995, p. 21-22) nos dados gerados. Tomamos como base para esta análise as mesmas categorias teóricas que nortearam as atividades propostas no caderno didático utilizado na oficina. Assim, organizamos e apresentamos as análises com foco no componente verbal da escrita e da reescrita do texto, a partir dos seguintes procedimentos:

1. quanto ao sistema semântico-discursivo de Ideação - identificação dos participantes central e periféricos do texto, análise de processos que indicam as relações nucleares e a sequência de atividades de que a biografada participa, de modo a verificar o campo de experiência do texto;

2. quanto ao sistema semântico-discursivo de Avaliatividade - identificação e análise dos elementos avaliativos em relação à biografada e às suas atividades, conforme os campos semânticos do subsistema atitude;

3. quanto ao gênero de texto - a partir dos resultados da análise linguística, segmentação do texto em etapas e fases

\footnotetext{
${ }^{7}$ Sobre a organização de bilhete orientador, ver Fuzer (2012). Outras estratégias de feedback são apresentadas por Menegassi e Gasparotto (2019).
} 
de gênero e confirmação do propósito sociocomunicativo;

4. quanto aos estratos contextual, semântico-discursivo e gramatical do sistema linguístico - comparação entre as duas versões produzidas para identificação de possíveis avanços no processo de construção conjunta e para a confirmação da eficácia da abordagem teórico-metodológica da Pedagogia com base em Gênero de texto para a leitura e a produção de textos no contexto escolar em questão.

\section{Análise e discussão}

Visando à preparação dos alunos para a escrita conjunta do texto, a dinamização do Ciclo de Ensino e Aprendizagem iniciou pelo momento de Desconstrução, com atividades de leitura detalhada de outros textos do mesmo gênero, por meio de atividades organizadas no caderno didático (CECCHIN; FUZER, 2018), que focalizou em recursos de linguagem típicos em relatos biográficos descritos por Martin e Rose (2008). A atividade representada na Figura 2 apresenta um relato biográfico com os elementos linguísticos que caracterizam a estrutura esquemática e realizam o propósito sociocomunicativo desse gênero de texto. Inspirada em Emília e Christie (2013), a atividade propõe aos alunos o reconhecimento das etapas e fases do relato biográfico, bem como as características linguísticas que as realizam. 
Figura 2: Exemplo de atividade de Desconstrução do gênero relato biográfico com foco na estrutura esquemática e principais recursos linguísticos

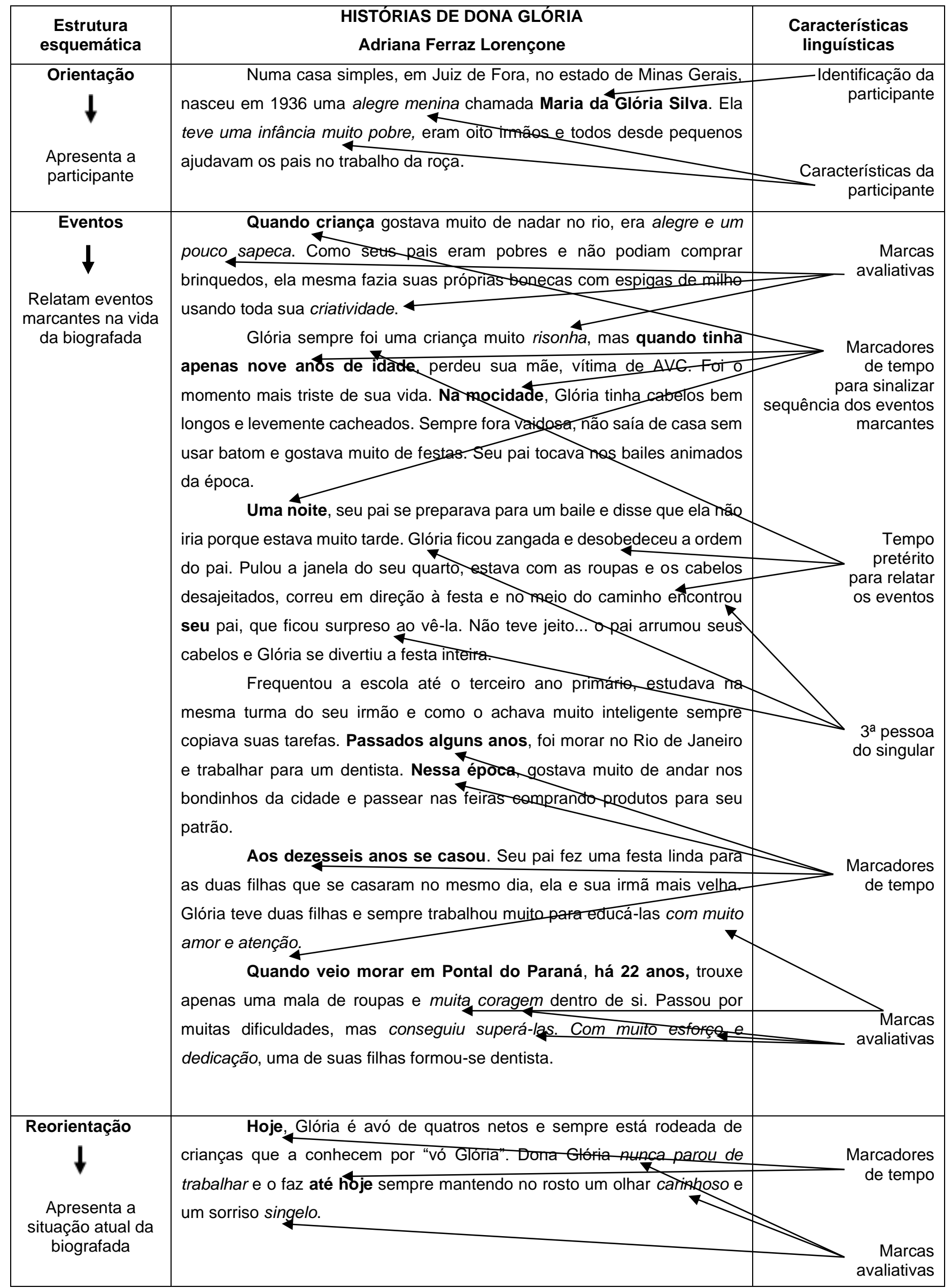

LORENÇONE, A.F. Publicado em 06 nov. 2012.Disponível em: <http://www.museudapessoa.net/pt/conteudo/historia/historias-de-dona-gloria47624>. Acesso em: 26 jul. 2018. (Adaptado) 
Após a realização das atividades do caderno didático, os alunos, a partir da proposta de produção (ver Anexo), produziram um texto conjuntamente. $\mathrm{Na}$ sequência, apresentamos a análise da versão escrita e da versão reescrita desse texto, cujos resultados estão organizados conforme a sequência de procedimentos descrita na seção anterior.

\subsection{Análise da escrita e reescrita do relato biográfico produzido conjuntamente}

Inicialmente, com base no estudo do sistema semântico-discursivo de Ideação (MARTIN, 1992; MARTIN; ROSE, 2007), foram identificados os participantes nucleares e periféricos do texto, considerando a estrutura da oração e as relações lexicais. A análise evidenciou que a biografada é nuclear em relação aos demais participantes tanto na versão escrita quanto na versão reescrita, isto é, ela é o centro da história relatada. Os demais participantes, classificados como periféricos, são a mãe, os filhos, os primos, o esposo e os meninos com quem brincava na rua, nas duas versões. Na versão reescrita, no entanto, foram acrescentadas duas participantes periféricas, a amiga e a professora da escola, devido à importância que, na opinião dos alunos-autores, estas têm na vida da biografada (Quadro 1).

Quadro 1: Participantes em cada versão do texto produzido conjuntamente

\begin{tabular}{|c|c|c|}
\hline Participante & Escrita (1 ${ }^{\text {a }}$ versão) & Reescrita ( (2 ${ }^{a}$ versão) \\
\hline Nuclear & biografada & biografada \\
\hline periféricos & $\begin{array}{c}\text { pai - mãe - primos } \\
\text { filhos - neto - } \\
\text { esposo - meninos } \\
\text { da rua }\end{array}$ & $\begin{array}{c}\text { pai - mãe - primos - } \\
\text { filhos - neto - esposo - } \\
\text { meninos da rua - } \\
\text { professora - amiga }\end{array}$ \\
\hline
\end{tabular}

Fonte: autoras.

A representação da participante nuclear como alguém que age e vivencia experiências junto aos participantes periféricos é o esperado em um relato biográfico, conforme Martin e Rose (2008) e Christie e Derewianka (2008), visto que esse gênero tem o propósito de enaltecer o/a participante, ressaltando os processos nos quais se envolve em diferentes fases da vida. Essa característica é evidenciada nas duas versões do texto. Na primeira, das 87 orações que constituem o texto, em 80 a biografada aparece como Agente dos processos e em 8 como Beneficiário; e na reescrita, das 105 orações do texto, em 102 a biografada aparece como Agente dos processos e em 3 como Beneficiário, conforme exemplifica o Quadro 2.

\section{Quadro 2: Participante nuclear como Agente e Beneficiário em cada versão do texto}

\begin{tabular}{|c|c|c|c|}
\hline \multicolumn{2}{|c|}{$\begin{array}{l}\text { Escrita } \\
\text { Processos em que a } \\
\text { biografada participa }\end{array}$} & \multicolumn{2}{|c|}{$\begin{array}{c}\text { Reescrita } \\
\text { Processos em que a biografada } \\
\text { participa }\end{array}$} \\
\hline $\begin{array}{l}\text { como } \\
\text { Agente }\end{array}$ & $\begin{array}{c}\text { como } \\
\text { Beneficiário }\end{array}$ & $\begin{array}{c}\text { como } \\
\text { Agente }\end{array}$ & $\begin{array}{c}\text { como } \\
\text { Beneficiário }\end{array}$ \\
\hline $\begin{array}{l}\text { gostava } \\
\text { de subir } \\
\text { em } \\
\text { árvores, } \\
\text { de jogar } \\
\text { futebol } \\
\text { com os } \\
\text { meninos } \\
\text { da sua } \\
\text { rua. } \\
\text { chutava } \\
\text { com o } \\
\text { pé para } \\
\text { extraviá- } \\
\text { las } \\
\text { ia para o } \\
\text { meio do } \\
\text { campo e } \\
\text { interferia } \\
\text { no jogo. }\end{array}$ & $\begin{array}{l}\text { sua professora } \\
\text { Ihe deixou de } \\
\text { castigo } \\
\text { sua tia Ihe } \\
\text { arranjou um } \\
\text { emprego } \\
\text { patrões de sua } \\
\text { mãe que } \\
\text { custearam }\end{array}$ & $\begin{array}{l}\text { interrompia } \\
\text { seus primos } \\
\text { no jogo de } \\
\text { bolita } \\
\text { dedicou-se à } \\
\text { criação dos } \\
\text { filhos } \\
\text { integralmente. } \\
\text { quando } \\
\text { novamente } \\
\text { pode passar } \\
\text { pela roleta do } \\
\text { ônibus, algo } \\
\text { simples }\end{array}$ & $\begin{array}{l}\text { sua tia, muito } \\
\text { solicita, Ihe } \\
\text { arranjou um } \\
\text { emprego como } \\
\text { auxiliar de } \\
\text { limpeza } \\
\text { Esse período } \\
\text { foi o mais } \\
\text { triste de sua } \\
\text { vida } \\
\text { sua mãe, } \\
\text { muito doente, } \\
\text { veio a falecer } \\
\text { sua família } \\
\text { passou por } \\
\text { necessidades } \\
\text { financeiras }\end{array}$ \\
\hline
\end{tabular}

Fonte: elaborado pelas autoras, com base em Martin (1992)

A participante nuclear se envolve em processos relacionais, materiais, mentais e verbais, com os quais assume, respectivamente, representações de Portador, Ator, Experienciador e Dizente, com o papel de Agente na maioria dos processos. Por meio dessas realizações léxicogramaticais, são representados alguns dos atributos da biografada, suas experiências interiores e seu discurso de aconselhamento aos jovens durante a entrevista, conforme exemplifica o Quadro 3 com algumas evidências verificadas nos textos. 
Quadro 3: Tipos de processos e funções experienciais desempenhadas pela biografada

\begin{tabular}{|c|c|c|c|}
\hline $\begin{array}{l}\text { Tipo de } \\
\text { processo }\end{array}$ & $\begin{array}{l}\text { Participante } \\
\text { biografada }\end{array}$ & $\begin{array}{l}\text { Exemplos na } \\
\text { escrita }\end{array}$ & $\begin{array}{l}\text { Exemplos na } \\
\text { reescrita }\end{array}$ \\
\hline Relacional & Portador & $\begin{array}{l}\text { apesar de ser } \\
\text { muito forte, } \\
\text { ficou } \\
\text { depressiva }\end{array}$ & $\begin{array}{lr}\text { Era } & \text { uma } \\
\text { menina } & \text { muito } \\
\text { arteira } & \end{array}$ \\
\hline Material & Ator & $\begin{array}{lr}\text { estragava a } \\
\text { linha das } \\
\text { pandorgas } \\
\text { subir em } \\
\text { árvores } \\
\text { tendo que } \\
\text { ajudar criar } \\
\begin{array}{l}\text { seus irmãos } \\
\text { mais novos }\end{array}\end{array}$ & $\begin{array}{l}\text { ela puxava a } \\
\text { linha, } \\
\text { ela chutava } \\
\text { com o pé para } \\
\text { extraviá-las, ia } \\
\text { para o meio do } \\
\text { campo } \\
\text { interferia no } \\
\text { jogo. }\end{array}$ \\
\hline Mental & Experienciador & $\begin{array}{l}\text { Ela lembra } \\
\text { emocionada } \\
\text { que, apesarde } \\
\text { ter passado } \\
\text { fome, frio } \\
\text { e ainda } \\
\text { dedicar-se aos } \\
\text { cuidados de } \\
\text { sua mãe } \\
\text { dedicou-se à } \\
\text { criação dos } \\
\text { filhos } \\
\text { integralmente } \\
\text { passou por } \\
\text { muitas } \\
\text { dificuldades } \\
\text { e relembra } \\
\text { com } \\
\text { satisfação um } \\
\text { momento } \\
\text { marcante }\end{array}$ & $\begin{array}{l}\text { passou por um } \\
\text { momento } \\
\text { marcante, que } \\
\text { lembra até } \\
\text { hoje } \\
\text { apesar de ter } \\
\text { passado fome, } \\
\text { frio, dormido } \\
\text { no chão, } \\
\text { nunca perdeu } \\
\text { sua força para } \\
\text { lutar pela vida } \\
\text { de sua mãe. } \\
\text { sentiu um forte } \\
\text { desejo de de } \\
\text { comer carne } \\
\text { de frango e de } \\
\text { beber Coca- } \\
\text { Cola lembra } \\
\text { Ela lemberionada } \\
\text { emocion } \\
\text { que, apesarde } \\
\text { ter passado } \\
\text { fome, frio }\end{array}$ \\
\hline Verbal & Dizente & $\begin{array}{l}\text { Ela contou que } \\
\text { sofreu } \\
\text { preconceito } \\
\text { Dona Regina } \\
\text { aconselha os } \\
\text { jovens } \\
\text { pedindo que } \\
\text { "não use as } \\
\text { drogas }\end{array}$ & $\begin{array}{l}\text { Ela } \\
\text { comemora: } \\
\text { "agora } \\
\text { ninguém mais } \\
\text { segura!". } \\
\text { pede aos } \\
\text { jovens que } \\
\text { aproveitem as } \\
\text { oportunidades } \\
\text { e jamais usem } \\
\text { as drogas, } \\
\text { "pois a droga } \\
\text { destrói a } \\
\text { família". }\end{array}$ \\
\hline
\end{tabular}

Fonte: elaborado pelas autoras a partir de categorias de Halliday e Matthiessen (2014).

O envolvimento da participante nuclear em diferentes atividades aponta para a presença de distintos campos de experiência presentes nas duas versões, os quais classificamos em: família, escola, diversão/lazer e trabalho. O campo religiosidade, no entanto, é apresentado somente na segunda versão, uma vez que, durante a atividade de reescrita, os alunos lembraram que, na entrevista, a biografada ressaltou várias vezes sua fé em Deus e, então, decidiram acrescentar esse campo no relato biográfico.

A partir dos campos, identificamos nas análises as atividades nas quais a biografada se envolve e que são relevantes ao longo de sua vida, o que contribui para a realização do propósito do gênero relato biográfico, qual seja, reportar eventos marcantes na vida de uma pessoa chave (MARTIN; ROSE, 2008),

A sequência de atividades realiza eventos que se instanciam nas etapas e fases que se desdobram no texto. Dessa forma, é possível sequenciar temporalmente as atividades em que a participante aparece envolvida, representada na Figura 3.

Figura 3: Sequência de atividades na escrita e na reescrita do relato biográfico

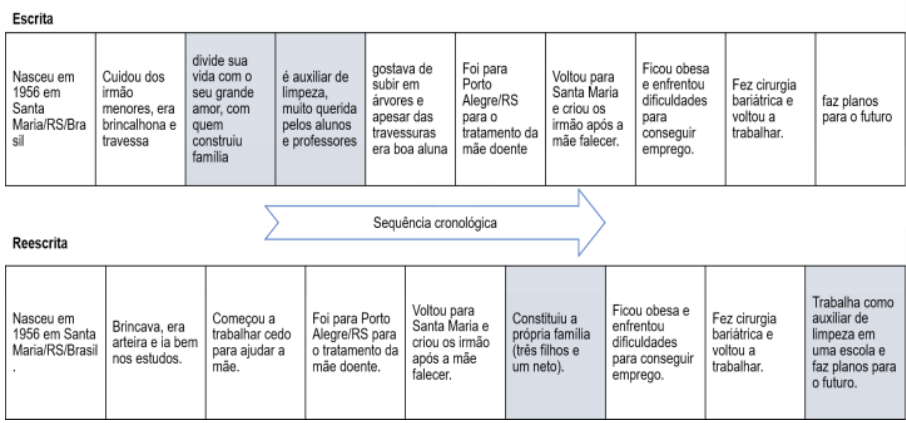

Fonte: as autoras.

A primeira versão do texto apresenta uma quebra de linearidade na sequência temporal, pois o relato parte de um momento atual em meio à fase da infância, o que foi reorganizado na reescrita a partir das orientações fornecidas.

Quanto ao sistema semântico-discursivo de Avaliatividade (MARTIN; WHITE, 2005), verificam-se, nas duas versões do texto, uma série de avaliações realizadas por meio de palavras, grupos de palavras e orações. No que se refere ao subsistema Atitude, 
sobressaem-se avaliações de afeto e de julgamento, como exemplifica o Quadro 4.

\section{Quadro 4: Avaliações relacionadas à biografada nas duas versões do texto}

\begin{tabular}{|c|c|c|}
\hline $\begin{array}{c}\text { Campo } \\
\text { semântico }\end{array}$ & Categorias & Exemplos \\
\hline \multirow[t]{2}{*}{ Afeto } & Satisfação & $\begin{array}{c}\text { gostava de subir em } \\
\text { árvore } \\
\text { lembra com } \\
\text { satisfação um } \\
\text { momento marcante } \\
\text { querida pelos alunos } \\
\text { e professores }\end{array}$ \\
\hline & Anormalidade & $\begin{array}{c}\text { sofreu preconceito } \\
\text { por estar obesa } \\
\text { ficou depressiva }\end{array}$ \\
\hline Apreciação & Valoração & $\begin{array}{c}\text { estudou em uma } \\
\text { escola particular } \\
\text { Era vaidosa e gostava } \\
\text { de se arrumar } \\
\text { e já tem planos }\end{array}$ \\
\hline \multirow{3}{*}{ Julgamento } & Tenacidade & $\begin{array}{c}\text { precisou encontrar } \\
\text { forças para continuar } \\
\text { sua vida e sustentar } \\
\text { seus irmãos } \\
\text { nunca perdeu sua } \\
\text { força para lutar pela } \\
\text { vida de sua mãe. } \\
\text { "agora ninguém mais } \\
\text { [me] segura!" }\end{array}$ \\
\hline & Capacidade & $\begin{array}{c}\text { ia bem nos estudos e } \\
\text { tirava boas notas. } \\
\text { batalharam pela sua } \\
\text { familia e } \\
\text { conseguiram criar } \\
\text { seus filhos }\end{array}$ \\
\hline & Normalidade & $\begin{array}{c}\text { ajudar nas despesas } \\
\text { da casa } \\
\text { cuidar de seus irmãos } \\
\text { e sua irmã }\end{array}$ \\
\hline
\end{tabular}

Fonte: elaborado pelas autoras a partir de categorias de Martin e White (2005)

As marcas avaliativas que denotam afeto positivo de satisfação podem se relacionar aos sentimentos de conquista, tais como: a satisfação em uma brincadeira de criança e em dividir a vida com seu grande amor; o amor pela sua família; o fato de conquistar o carinho de alunos e professores da escola onde trabalha e ser convidada para ser biografada. Dessa forma, a biografada é representada como uma pessoa amorosa e, ao mesmo tempo, lutadora que, apesar dos obstáculos e dificuldades que precisou enfrentar ao longo da vida, sempre buscou garantir o sustento de sua família e cuidar da mãe doente e dos irmãos.

A representação de uma mulher lutadora se realiza com a contribuição das marcas avaliativas de julgamento de estima social, nas categorias tenacidade, capacidade e normalidade. Mesmo diante das adversidades, como dificuldades financeiras, doença e falecimento de sua mãe, a depressão e obesidade, sua tenacidade não the permitiu desistir, denotando "quão resoluta" (MARTIN; WHITE, 2005, p. 52) ela demonstra ser. Em seu conjunto, as marcas avaliativas usadas nas duas versões do texto caracterizam a história de vida difícil de uma pessoa que tem a capacidade de se reconstruir, mostrando-se resiliente, solidária, perseverante, cooperativa e afetuosa com as pessoas ao seu redor.

Com relação à estrutura esquemática, a análise evidencia as etapas obrigatórias do gênero relato biográfico: na Orientação, destacam-se informações sobre o nascimento da biografada; na etapa Eventos, são relatadas situações que dizem respeito à infância, à adolescência e à maturidade da biografada; na Avaliação, é informada a motivação que levou os autores a escolherem a participante para ser homenageada com a biografia. A partir dos resultados da análise do sistema de Ideação que evidenciou os campos no discurso, verificamos que as fases podem ser associadas aos momentos da vida da biografada e, por isso, as nomeamos como: nascimento, infância, adolescência, maturidade, projeção para o futuro e motivação. O Quadro 5 sumariza essa organização. 
Quadro 5: Etapas e fases identificadas nas duas versões do relato biográfico produzido conjuntamente

\begin{tabular}{|c|c|c|}
\hline \multicolumn{2}{|c|}{ Escrita } & Reescrita \\
\hline Etapas & Fases & Fases \\
\hline Orientação & nascimento & Nascimento \\
\hline Eventos & $\begin{array}{l}\text { infância } \\
\text { maturidade } \\
\text { infância } \\
\text { adolescência } \\
\text { maturidade } \\
\text { projeção para o } \\
\text { futuro }\end{array}$ & $\begin{array}{l}\text { Infância } \\
\text { adolescência } \\
\text { maturidade } \\
\text { projeção para o } \\
\text { futuro }\end{array}$ \\
\hline Avaliação & conselho & motivação \\
\hline
\end{tabular}

Fonte: elaborado pelas autoras

As Etapas do texto produzido (Quadro 5) se correspondem da escrita e da reescrita, contemplando a estrutura do gênero de texto estudado. No entanto, constatou-se que, na escrita, o texto apresentava algumas inadequações em relação à Fase correspondente à maturidade, que estava deslocada na Fase da infância. Essa inadequação interferia na construção do gênero, em razão da relevância da sequência cronológica. Outra questão refere-se à Etapa Avaliação, que na escrita se constituía do conselho dado aos jovens pela biografada e na reescrita há a inserção da motivação para a escolha de biografar essa pessoa. Essas considerações estão destacadas no Quadro 5.

Assim, relacionamos as fases que compõem as etapas do gênero aos campos de experiência identificados no texto, tendo como base as atividades nas quais a participante aparece envolvida. Os dados referentes à escrita estão sumarizados no Quadro 6. 
Quadro 6: Relação entre campos de experiência, atividades, etapas e fases na escrita do relato biográfico

\begin{tabular}{|c|c|c|c|}
\hline Etapas & Fases & Campos de experiência & Atividades evidenciadas na escrita \\
\hline Orientação & Nascimento & Família & $\begin{array}{l}\text { Nascia, no Hospital de Caridade Astrogildo de } \\
\text { Azevedo, no coração do Rio Grande do Sul, em } \\
\text { setembro de } 1956 \text { - órfã de pai - }\end{array}$ \\
\hline \multirow{5}{*}{ Eventos } & Infância & $\begin{array}{l}\text { Família } \\
\text { Diversão/ } \\
\text { Lazer } \\
\text { Escola }\end{array}$ & $\begin{array}{l}\text { cuidou de seus três irmãos - era brincalhona e } \\
\text { travessa - interrompia seus primos no jogo - } \\
\text { estragava a linha das pandorgas - cresceu num } \\
\text { bolicho velho - brincando com seus amigos }\end{array}$ \\
\hline & Maturidade & $\begin{array}{l}\text { Família } \\
\text { Trabalho }\end{array}$ & $\begin{array}{c}\text { divide sua vida com o seu grande amor - com quem } \\
\text { construiu uma linda família - é auxiliar de limpeza no } \\
\text { Instituto São José - é muito querida pelos alunos e } \\
\text { professores. }\end{array}$ \\
\hline & Infância & $\begin{array}{l}\text { Família Diversão/ } \\
\text { lazer } \\
\text { Escola }\end{array}$ & $\begin{array}{l}\text { gostava de subir em árvores - de jogar futebol - até } \\
\text { os } 15 \text { anos brincou de bonecas de pano feitas pela } \\
\text { sua avó - era boa aluna - ia bem na escola - tirava } \\
\text { boas notas - assoviou na aula - ficou de castigo - } \\
\text { seus responsáveis foram chamados - estudou em } \\
\text { uma escola particular - os patrões de sua mãe, } \\
\text { custeavam os seus estudos }\end{array}$ \\
\hline & Adolescência & $\begin{array}{l}\text { Escola } \\
\text { Família } \\
\text { Diversão/ } \\
\text { Lazer } \\
\text { Trabalho }\end{array}$ & $\begin{array}{c}\text { era vaidosa - gostava de ir a bailes, saraus, de } \\
\text { paquerar - precisou abandonar os estudos - teve de } \\
\text { cuidar de sua mãe doente - teve que trabalhar para } \\
\text { comprar os medicamentos - passou por dificuldade e } \\
\text { necessidades - passou fome, frio dormiu no chão - } \\
\text { nunca perdeu sua força - teve que mudar-se para } \\
\text { Porto Alegre - ficou na casa de uma tia - trabalhou } \\
\text { para ajudar nas despesas - conheceu jogadores e } \\
\text { personalidades importantes - contribuiu com a } \\
\text { manutenção da casa do seu time do coração - voltou } \\
\text { para Santa Maria - sua mãe faleceu - precisou } \\
\text { encontrar forças para continuar sua vida e sustentar } \\
\text { seus irmãos - casou-se - dedicou-se à criação dos } \\
\text { filhos }\end{array}$ \\
\hline & Maturidade & $\begin{array}{l}\text { Família } \\
\text { Trabalho }\end{array}$ & $\begin{array}{c}\text { ficou obesa - teve dificuldades para conseguir um } \\
\text { emprego - sofreu preconceito por estar obesa - ela e } \\
\text { seu marido conseguiram criar seus filhos - passou } \\
\text { por muitas dificuldades - batalhou pela sua família - } \\
\text { fez a bariátrica - relembra momento marcante - pode } \\
\text { passar pela roleta do ônibus - algo que ela não podia } \\
\text { fazer. }\end{array}$ \\
\hline Avaliação & $\begin{array}{l}\text { Projeção para o } \\
\text { futuro }\end{array}$ & $\begin{array}{l}\text { Família } \\
\text { Diversão/ } \\
\text { lazer }\end{array}$ & $\begin{array}{l}\text { quando estiver aposentada tem planos - abrir um } \\
\text { negócio familiar - poder morar na área rural - de voltar } \\
\text { a dançar em bailes - frequentar o CTG - ensinar seu } \\
\text { marido a dançar - aconselha os jovens }\end{array}$ \\
\hline
\end{tabular}

Fonte: elaborado pelas autoras.

$\mathrm{Na}$ análise da primeira versão, verificamos que o texto apresenta informações que dizem respeito à maturidade inserida na fase da infância. A partir das orientações fornecidas em aula, o texto foi reorganizado pelos alunos-autores no momento da reescrita, conforme indicam os dados sumarizados no Quadro 7. 
Quadro 7: Relação entre campos de experiência, atividades, etapas e fases na reescrita do relato biográfico

\begin{tabular}{|c|c|c|c|}
\hline Etapas & Fases & $\begin{array}{l}\text { Campos de } \\
\text { experiência }\end{array}$ & Atividades evidenciadas na reescrita \\
\hline Orientação & Nascimento & Família & $\begin{array}{l}\text { nascia em 1956, na cidade de Santa Maria/RS/Brasil - foi criada } \\
\text { pela sua mãe, sua avó e seu tio - crescera - não conheceu seu pai }\end{array}$ \\
\hline \multirow{4}{*}{ Eventos } & Infância & $\begin{array}{l}\text { Família } \\
\text { Diversão/Lazer } \\
\text { Escola }\end{array}$ & $\begin{array}{l}\text { gostava de subir em árvores - de jogar futebol com os meninos -. } \\
\text { era uma menina muito arteira - ela puxava a linha, ela chutava com } \\
\text { o pé - ela ia para o meio do campo e interferia no jogo - assobiou } \\
\text { na aula - ia bem nos estudos - estudou em escola particular - fez } \\
\text { uma amiga que conserva até hoje. }\end{array}$ \\
\hline & Adolescência & $\begin{array}{l}\text { Escola } \\
\text { Família } \\
\text { Diversão/Lazer } \\
\text { Trabalho }\end{array}$ & $\begin{array}{l}\text { brincava de bonecas - começou a sair - era vaidosa - gostava de se } \\
\text { arrumar - tinha suas - precisou abandonar os estudos para ajudar } \\
\text { nas despesas - comprar os medicamentos da mãe - para cuidar de } \\
\text { seus irmãos e sua irmã - mudou-se com a família para o bairro } \\
\text { Urlândia - precisaram ir para Porto Alegre - ficou hospedada na } \\
\text { casa de uma tia - passou por diversas dificuldades e necessidades } \\
\text { - passou fome, frio dormiu no chão - nunca perdeu sua força - } \\
\text { voltou para Santa Maria - precisou encontrar forças para continuar } \\
\text { sua vida - sustentar seus irmãos }\end{array}$ \\
\hline & Maturidade & $\begin{array}{l}\text { Família } \\
\text { Trabalho }\end{array}$ & $\begin{array}{l}\text { ficou obesa - teve dificuldades para conseguir um emprego - sofreu } \\
\text { preconceito por sua condição física - batalharam pela família } \\
\text { conseguiram criar seus filhos - fez a cirurgia bariátrica - mudou seu } \\
\text { estilo de vida - pode passar pela roleta do ônibus - é auxiliar de } \\
\text { limpeza - é muito querida pelos alunos e professores }\end{array}$ \\
\hline & $\begin{array}{l}\text { Projeção para o } \\
\text { futuro }\end{array}$ & $\begin{array}{l}\text { Família } \\
\text { Diversão/lazer } \\
\text { Religiosidade }\end{array}$ & $\begin{array}{l}\text { quando estiver aposentada tem planos de abrir um negócio familiar } \\
\text { - poder morar na área rural - irá poder realizar seu desejo de voltar } \\
\text { a dançar em bailes e frequentar o CTG - terá de ensinar seu gringo } \\
\text { - aconselha os jovens - tem muita fé em Deus e no futuro - } \\
\text { aconselha os jovens }\end{array}$ \\
\hline Avaliação & Motivação & & $\begin{array}{l}\text { foi a escolhida por ser muito carismática e simpática em nosso } \\
\text { colégio - temos muito carinho por ela - nos levou a querer conhecer } \\
\text { mais sobre sua vida - homenageá-la }\end{array}$ \\
\hline
\end{tabular}

Fonte: elaborado pelas autoras

$\mathrm{Na}$ segunda versão do texto, os problemas identificados na análise da primeira versão foram solucionados pelos alunos-autores com o auxílio das mediadoras. Além disso, verificou-se que, na reescrita, foi incluído um novo campo, que se refere à religiosidade na fase de projeção para o futuro. Essa inserção permitiu contemplar a manifestação de fé pela biografada, algo recorrente em sua fala na entrevista, percebida pelos alunos no momento da reescrita do texto. Ademais, na etapa Avaliação foi inserida a fase motivação com referência ao que levou os estudantes a escolherem biografar essa funcionária da instituição.

Tendo em vista as variáveis do texto, os sistemas semântico-discursivos de Ideação e Avaliatividade e o sistema léxico-gramatical de Transitividade, sistematizamos critérios de avaliação para relato biográfico, partindo do que propõem Rose e Martin (2012), e analisamos as duas versões do relato biográfico produzido durante a Construção conjunta, como mostra o Quadro 8. 
superordenação e de composição nas duas versões do

Quadro 8: Comparação entre a versão escrita e a reescrita do texto com base em critérios de avaliação para o gênero relato biográfico

\begin{tabular}{|c|c|c|c|}
\hline \multicolumn{2}{|l|}{ Contexto } & \multirow{2}{*}{$\begin{array}{l}\text { Escrita } \\
\text { Sim }\end{array}$} & \multirow{2}{*}{ Reescrita } \\
\hline 1.Propósito & $\begin{array}{l}\text { O texto é apropriado e bem desenvolvido em relação ao } \\
\text { propósito da escrita do gênero relato biográfico? }\end{array}$ & & \\
\hline 2. Etapa & $\begin{array}{l}\text { O texto apresenta as etapas do relato biográfico bem } \\
\text { desenvolvidas? }\end{array}$ & Sim & $\operatorname{sim}$ \\
\hline 3. Fase & As Fases do texto são sequenciadas e bem organizadas? & às vezes & $\operatorname{sim}$ \\
\hline 4. Campo & O escritor entende e explica o campo no relato biográfico? & às vezes & $\operatorname{sim}$ \\
\hline 5. Relações & O escritor informa bem o leitor sobre o biografado? & Sim & $\operatorname{sim}$ \\
\hline 6. Modo & A linguagem é adequada para o nível escolar? & Sim & $\operatorname{sim}$ \\
\hline \multicolumn{4}{|l|}{ Discurso } \\
\hline 7. Ideação & O léxico é bem utilizado para construir o campo? & $\operatorname{sim}$ & $\operatorname{sim}$ \\
\hline 8. Avaliatividade & Os recursos avaliativos são bem utilizados pelo escritor? & $\operatorname{sim}$ & $\operatorname{sim}$ \\
\hline \multicolumn{4}{|c|}{ Gramática e recursos linguísticos } \\
\hline 9.Gramática & $\begin{array}{l}\text { Há uma variedade apropriada de sentença e estruturas de grupo } \\
\text { de palavra para o nível escolar? } \\
\text { As convenções gramaticais da língua portuguesa escrita são } \\
\text { utilizadas adequadamente? }\end{array}$ & $\begin{array}{l}\operatorname{sim} \\
\text { às vezes }\end{array}$ & $\operatorname{sim}$ \\
\hline 10. Pontuação & A pontuação é utilizada de forma apropriada e precisa? & às vezes & $\operatorname{sim}$ \\
\hline 11. Apresentação & Os parágrafos são utilizados e o layout é claro? & às vezes & Sim \\
\hline
\end{tabular}

Fonte: elaborado e adaptado pelas autoras com base em Rose e Martin (2012)

No nível do contexto, é constatada significativa melhora na organização das fases e do campo de experiência na versão reescrita em comparação com a primeira versão. A falta de linearidade temporal que prejudicava o fluxo dos eventos da vida da biografada, verificada na primeira versão, foi resolvida por meio da reorganização dos eventos em ordem cronológica na segunda versão, o que possibilitou atender melhor à característica do gênero (MARTIN; ROSE, 2008). Além disso, os alunos-autores sentiram a necessidade de incluir 0 campo de experiência religiosidade, percebida por eles como recorrente na fala da entrevistada, e a inclusão da motivação que os levou a escolher essa pessoa para ser biografada.

No nível da semântica do discurso, a análise das relações lexicais evidencia taxonomias de texto, com foco na Entidade, conforme apresentam alguns exemplos no Quadro 9.

Quadro 9: Exemplos de relações lexicais evidenciadas nas duas versões do texto

\begin{tabular}{|l|l|l|}
\hline Taxonomias & Categoria & Exemplos \\
\hline Superordenação & Repetição & $\begin{array}{l}\text { Com as dificuldades, ela } \\
\text { e seu marido conseguiram } \\
\text { criar seus filhos. Passou } \\
\text { por muitas dificuldades e } \\
\text { sempre batalhou pela sua } \\
\text { família. }\end{array}$ \\
\cline { 2 - 3 } & \multirow{2}{*}{ Oposição } & $\begin{array}{l}\text { Órfã de pai, cuidou de } \\
\text { seus três irmãos frutos do } \\
\text { segundo casamento de } \\
\text { sua mãe. }\end{array}$ \\
\cline { 2 - 3 } & $\begin{array}{l}\text { [...] nascia Maria Regina } \\
\text { dos Santos Lopes Silveira, } \\
\text { em setembro de 1956. } \\
\text { Em 1996, casou-se ]...] }\end{array}$ \\
\hline
\end{tabular}




\begin{tabular}{|l|l|l|}
\hline & Hiperonímia & $\begin{array}{l}\text { interrompia seus primos } \\
\text { no jogo de bolita e, às } \\
\text { vezes, estragava a linha } \\
\text { das pandorgas. }\end{array}$ \\
\hline Composição & Meronímia & $\begin{array}{l}\text { uma linda família, formada } \\
\text { pelos filhos Ana Luiza, } \\
\text { Felipe e Mariana e pelo } \\
\text { netinho Braian Lucas. }\end{array}$ \\
\hline
\end{tabular}

Fonte: elaborado pelas autoras

Relações lexicais avaliativas de Atitude, características do relato biográfico, de acordo com Martin e Rose (2008) são usadas, no texto resultante da Construção conjunta, para enaltecer a força e a perseverança da biografada ao reportar os eventos que foram significativos em sua vida, contribuindo para realizar o propósito sociocomunicativo desse gênero de texto.

No nível da gramática, a análise da primeira versão do texto revelou a necessidade de algumas adequações para atender às convenções da escrita, como, por exemplo, a grafia em regina teve dificuldades, conscientização qnto ao uso das drogas, destrói qlar família.

Esse processo de produção conjunta de um relato biográfico contribuiu significativamente para a realização da próxima estratégia do Ciclo de Ensino e Aprendizagem: a construção individual (ROSE; MARTIN, 2012). O texto resultante da Construção conjunta foi publicado em uma coletânea (CECCHIN; MOURA; FUZER 2018), juntamente com as produções individuais desse mesmo gênero de texto.

\section{Considerações finais}

Os resultados das análises do componente verbal da primeira versão de um relato biográfico produzido conjuntamente por alunos da educação básica, com a mediação do professor, deixam claro o papel das atividades de Desconstrução e de Construção conjunta como estratégias para o ensino de leitura e escrita em língua portuguesa com base em gêneros de texto, na educação básica. $A$ análise de cada versão do texto produzido conjuntamente pelos alunos evidenciou progressiva aproximação ao domínio do gênero de texto em foco.
No que se refere aos significados ideacionais, a participante biografada é representada como o núcleo das interações e dos significados experienciais. A sequência de atividades e os campos de experiência nos quais a participante nuclear se envolve possibilitaram identificar fases consideradas relevantes ao longo de sua história de vida, as quais, no texto produzido conjuntamente pelos alunos, constituem as etapas fundamentais do gênero relato biográfico.

Os significados avaliativos, usados especialmente na versão reescrita, corroboram a representação de uma pessoa amorosa e zelosa com a família. Ocorrências do campo semântico de julgamento se sobressaem em comparação com as ocorrências de afeto e apreciação, indicando que a tenacidade e resiliência ao superar as dificuldades (especialmente em favor da família) foram aspectos que os alunos-autores escolheram destacar sobre a vida da biografada.

Esses resultados indicam o atendimento do texto produzido conjuntamente pelos alunos aos critérios de avaliação que dizem respeito aos recursos semântico-discursivos mais relevantes para a realização do propósito sociocomunicativo do gênero relato biográfico. As atividades de escrita e reescrita conjunta do texto possibilitaram aos alunos colocarem em prática conhecimentos trabalhados durante as atividades de Desconstrução, visando à preparação para a escrita, por meio da realização de atividades do caderno didático, o qual, por sua vez, foi elaborado pela professora com base nos resultados das análises de textos selecionados para a modelagem.

$$
\text { O desdobramento dos resultados }
$$

evidenciados neste artigo, constituirão um próximo passo da pesquisa que visa a análise dos textos produzidos durante a Construção individual do Ciclo de Ensino e Aprendizagem (ROSE; MARTIN, 2012), a fim de verificar em que medida 0 uso de recursos linguísticos estudados e praticados com a ajuda dos colegas e da professora se evidencia na produção individual de um novo texto do mesmo gênero, de maneira mais autônoma. 
No que se refere, portanto, às estratégias de Desconstrução e Construção conjunta, a Pedagogia com base em Gêneros de Texto revelou-se, na experiência analisada neste artigo, uma importante metodologia para conduzir o processo de ensino e aprendizagem de produção textual em Língua Portuguesa, reafirmando a eficiência da metodologia aplicada e analisada em outras experiências e pesquisas anteriores, com diferentes gêneros de texto em diferentes níveis de ensino no contexto brasileiro, como o Estudo de caso em língua inglesa no ensino superior por Santorum (2019), o relato autobiográfico no Ensino de Jovens e Adultos por Nascimento (2017), as notícias jornalísticas por Pires (2017), as narrativas, os relatos e as observações (comentários) por Sousa (2016) e as narrativas por Silva (2016).

Mais especificamente, os resultados da análise das ocorrências de Ideação e de Avaliatividade, mostradas no presente artigo, apontam para a relevância do ensino de recursos linguísticos categorizados nesses sistemas semântico-discursivos para a compreensão das etapas e fases necessárias à produção de um texto que realize o propósito de relatar histórias de vida. Em outras palavras, o ensino de recursos ideacionais e avaliativos da língua portuguesa precisa ser propiciado aos alunos para que possam ler com proficiência e produzir não só relatos biográficos, como também quaisquer textos que envolvam representações e avaliações. O relato biográfico, neste caso, é um dos contextos ou ambientes propícios para o trabalho com tais potencialidades da linguagem, assim como a Construção conjunta é uma estratégia importante para dar apoio ao aprendizado de tais recursos linguísticos pelos alunos. Assim entendemos o "ensino contextualizado da língua portuguesa" para a educação básica.

\section{Agradecimentos}

Agradecemos a direção do Instituto São José, pela disponibilização da infraestrutura necessária à execução do projeto na escola; a Camila Berlezi de Moura, pela colaboração como bolsista FIEX UFSM na oficina do Ateliê de Textos em que se desenvolveram as atividades relatadas neste trabalho; aos alunos participantes do projeto, pelo empenho durante todo o processo desenvolvido; ao Fundo de Incentivo à Extensão da UFSM, pela bolsa concedida à graduanda de Letras que colaborou durante a oficina; ao Centro de Artes e Letras, pelo apoio financeiro para a impressão de exemplares do caderno didático utilizado na oficina.

\section{REFERÊNCIAS}

BRASIL. Ministério da Educação. Base Nacional Comum Curricular. Brasília, 2018.

CECCHIN, A. S.; FUZER, C. Ateliê de Textos: atividades de leitura e produção de biografias multimodais. Caderno Didático. Santa Maria: UFSM, PPGL, 2018.

CECCHIN, A. S.; MOURA, C. B.; FUZER, C. (Org.) Pessoas especiais, histórias extraordinárias. Santa Maria, RS: UFSM, CAL, Ateliê de Textos, 2018.

CECCHIN, A. S. Investigação de uma proposta de produção de histórias com base na Linguística Sistêmico-Funcional. Registro GAP/CAL ํㅜ 046116. Santa Maria, CAL, UFSM, 2017.

CHRISTIE, F; DEREWIANKA, B. School Discourse: Learning to Write Across the Years of Schooling. Continuun: New York, 2008.

FUZER, C. Ateliê de Textos: práticas orientadoras para produção e avaliação de textos na perspectiva sistêmicofuncional. Registro GAP/CAL nํ 040190. Santa Maria: CAL, UFSM, 2016a. Disponível em: www.ufsm.br/ateliedetextos. Acesso em: 06 set. 2019.

FUZER, C. Produção textual na escola: subsídios para formação do professor. Santa Maria: UFSM, CAL, DLV, $2016 b$.

FUZER, C. Bilhete orientador como instrumento de interação no processo ensino-aprendizagem de produção textual. Letras, Santa Maria, n. 44, p. 213-245, 2012.

HALLIDAY, M. A. K. Introduction to Functional Grammar, London: Edward Arnold, 1985.

HALLIDAY, M.; MATTHIESSEN, C.M.I.M. Introduction to functional grammar. London: Routledge, 2014.

HALLIDAY; HASAN, R. Language, context, and text: aspects of language in a social-semiotic perspective. Oxford: Oxford University Press, 1989.

MARTIN, J. English text: System and Structure. Philadelphia, Amsterdam: John Benjamins Publishing Company, 1992.

MARTIN, J. R.; WHITE, P. R. R. The language of evaluation: appraisal in English. Palgrave Macmillan: New York, 2005. 
MARTIN, J. R.; ROSE, D. Genre Relations: Mapping Culture. Equinox: UK, 2008.

MARTIN, J.; ROSE, D. Working with discourse: meaning beyond the clause. London: Continuum, 2007.

MENEGASSI, R.J.; GASPAROTTO, D.M. Revisão dialógica: princípios teórico-metodológicos. Linguagem em (Dis)curso - LemD, Tubarão, SC, v. 19, n. 1, p. 107124, jan./abr. 2019. DOI: http://dx.doi.org/10.1590/19824017-190107-4518.

\section{OLIVEIRA, S.M.N. Relatos autobiográficos à luz da}

Pedagogia de Gêneros: uma trajetória com intervenção em classe de alunos de PROEJA. Tese (Doutorado em Letras) - Programa de Pós-Graduação em Letras, Universidade Federal de Santa Maria, Santa Maria, RS, 2017. Disponível em:

$<$ http://www.isfla.org/Systemics/Print/Theses/doNascime nto.pdf>. Acesso em: 08 set. 2019.

PIRES, Z. C. Unindo as pontas da teoria e da prática: contribuições da Pedagogia de Gêneros sob o viés da Linguística Sistêmico-Funcional na leitura e na escrita de notícias jornalísticas. Dissertação (Mestrado em Letras) Programa de Pós-Graduação em Letras, Universidade Federal do Rio Grande do Sul, Porto Alegre, 2017.

ROSE, D.; MARTIN, J. R. Learning to Write, Reading to Learn: Genre, Knowledge and Pedagogy in the Sydney School. London: Equinox, 2012.

SANTORUM, K.A.T. O efeito tridimensional obtido com o Ciclo Reading to Learn - a conscientização de uma metalinguagem pedagógica - emoldurado pela Linguística Sistêmico-Funcional. Tese (Doutorado em Letras) - Programa de Pós-Graduação em Letras, Universidade Federal do Rio Grande do Sul, Porto Alegre, 2019

SILVA, V. M. Ciclo de Ensino Aprendizagem na escola e estórias escritas: um estudo dos problemas fonoortográficos. Dissertação (Mestrado Profissional em Letras - PROFLETRAS) - Universidade de Pernambuco, 2016.

SOUSA, M. Ciclo de ensino, gramática e contexto: um estudo do uso dos processos em estórias. Dissertação (Mestrado Profissional em Letras - PROFLETRAS) Universidade de Pernambuco, 2016.

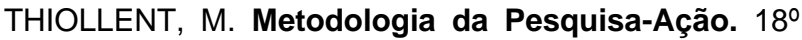
Ed. São Paulo: Cortez, São Paulo, 2011.

VIAN JR., O. Linguística Sistêmico-Funcional, Linguística Aplicada e Linguística Educacional. In: MOITA LOPES, L. P. (Org.) Linguística Aplicada na modernidade recente: festschriff para Antonieta Celani. $1^{\circ}$ Edição, Cap. 5, São Paulo: Parábola, 2013.

\section{Proposta de produção textual}

\section{A vida é feita de histórias}

Você sabia que existe uma editora especializada em registrar e eternizar histórias de pessoas comuns, unindo literatura e jornalismo? A jornalista e escritora Josiane Duarte criou a editora Memorabília (em alusão a fatos e coisas dignos de memória, lembranças). A ideia surgiu quando a avó de Josiane, Honorina Duarte, completou 100 anos, em 2005, e a autora decidiu homenageá-la com uma biografia. Para isso, fez entrevistas, pesquisou fotos de família e descobriu vários casos curiosos.

"A imensa maioria não conhece a história da sua família, e recolher essas histórias para contá-las de forma literária ajuda a perpetuar e valorizar a história familiar, saber de onde viemos, quem é a nossa família."

“O ideal é saber 'peneirar' o que há de melhor em cada história. Você tem que saber perguntar e depois contar isso de uma forma agradável."

Adaptado de: http://g1.globo.com/rio-dejaneiro/noticia/2010/10/escritora-cria-biografias-de-anonimos.html. Acesso em: 15 jul. 2018. biografia?

E você, quem gostaria de homenagear com uma

Para produzi-la, siga algumas orientações.

a) Escolha alguém importante que você queira homenagear. Pode ser um familiar, um amigo ou outra pessoa especial cuja história de vida você gostaria que mais pessoas conheçam.

b) Planeje como será escrito seu texto. Inicie com a identificação da pessoa escolhida. Você pode relatar eventos da infância, da adolescência, momentos de alegria, de dificuldade, de superação...

c) Faça um rascunho para organizar seu texto e só passe a limpo depois de fazer uma revisão cuidadosa.

d) Quando o texto estiver na versão final, fotografe ou procure uma foto representativa da pessoa biografada ou de cenários que lembrem essa pessoa.

e) A biografia pode ser lida pela própria pessoa biografada e por tantas outras pessoas interessadas em histórias de vida.

Após o processo de escrita e reescrita, seu texto poderá ser publicado em uma coletânea organizada pela equipe do Ateliê de Textos, e você poderá participar da sessão de lançamento em sua escola.
FUZER, Cristiane; CECCHIN, Anidene de Siqueira DESCONSTRUÇÃO E CONSTRUÇÃO CONJUNTA DE RELATO BIOGRÁFICO: IDEAÇÃO E AVALIATIVIDADE NA PERSPECTIVA SISTÊMICO-FUNCIONAL. Signo, Santa Cruz do Sul, v. 46, n. 86, maio 2021. ISSN 1982$2014 . \quad$ Disponível em: $<$ https://online.unisc.br/seer/index.php/signo/article/view/ 15891>.doi:https://doi.org/10.17058/signo.v46i86.15891. 